\title{
Diferentes ofertas de forragem e a produção de leite em vacas mestiças Holandês x Gir
}

\author{
Different herbage allowances and milk yield in crossbred Holstein x Gir
}

\author{
Fernanda Batistel ${ }^{\mathrm{I}}$ Jonas de Souza ${ }^{\mathrm{I}}$ Elvis Ticiani ${ }^{\mathrm{II}}$ Michel Baldinn' ${ }^{\mathrm{III}}$ Ricardo Dresch ${ }^{\mathrm{III}}$ \\ Diego Fernandes ${ }^{\mathrm{III}}$ Dimas Estrasulas de Oliveira ${ }^{\text {IV }}$
}

\section{RESUMO}

Objetivou-se avaliar o efeito de diferentes ofertas de forragem em pastagem de estrela africana (Cynodon nlemfuensis Vanderyst var. nlemfuensis), sobre a taxa de desaparecimento de forragem (TDF) e a produção de leite de vacas mestiças Holandês $x$ Gir. Trinta animais foram submetidos a três ofertas de forragem (OF) distintas, sendo 10,0 12,5 e $15,0 \%$ do peso corporal. Houve influência da OF sobre a TDF $(\mathrm{P}<0,001)$. Para cada unidade de acréscimo da OF, a TDF aumentou $140,0 \mathrm{~kg} \mathrm{ha} \mathrm{hia}^{-1}$. Houve efeito da relação folha:colmo sobre a produção de leite $(P<0,05)$. O aumento da oferta não refletiu em incremento da produção de leite em função do manejo empregado para obtenção das ofertas $e$ estádio de crescimento das plantas.

Palavras-chave: Cynodon, desempenho animal, pastagem tropical, relação folha:colmo.

\section{ABSTRACT}

The objective of this study was to evaluate different herbage allowances in stargrass (Cynodon nlemfuensis Vanderyst var. nlemfuensis), on the herbage disappearance rate (HDR) and milk yield in crossbred Holstein x Gir cows. Thirty animals were assigned to three different herbage allowances (HA), ranging from 10.0, 12.5 and 15.0\% BW. There was effect of HA on the HDR $(P<0.001)$. Increasing the HA in one unit had effect on the HDR increasing by $140.0 \mathrm{~kg} \mathrm{ha}^{-1}$ day1. There was effect of leaf:stem ratio on milk yield $(P<0.05)$. The increasing in supplying herbage allowances did not resulted in increased milk yield because the management for herbage allowance and herbage growth.

Key words: Cynodon, animal performance, tropical pasture, leaf:stem ratio.

\section{INTRODUÇÃO}

As forrageiras tropicais são a base da dieta do rebanho bovino brasileiro em virtude da disponibilidade, alto potencial produtivo e adaptação aos diversos ecossistemas brasileiros (SILVA, 2009) e que, quando bem manejadas, são capazes de sustentar níveis satisfatórios de produção de leite, sobretudo nas épocas mais favoráveis do ano (GOMIDE et al., 2001). Nesse contexto, as gramíneas do gênero Cynodon são capazes de produzir grandes quantidades de matéria seca (MS), com boa relação folha:colmo, sendo, então, apropriadas para alimentação animal, tanto sob a forma de pasto ou feno (GONÇALVES et al., 2002; REIS et al., 2005).

Estudos em pastagens temperadas mostraram que o incremento da oferta de forragem aumentou a produção de leite (McEVOY et al., 2008; RIBEIRO FILHO et al., 2009; CURRAN et al., 2010). Em contrapartida, em pastagens tropicais, os resultados são contraditórios, sendo que alguns comprovaram efeito positivo (COWAN et al., 1977; STOBBS, 1977) e outros não encontraram relação entre ambos (STRADIOTTI Jr., 1995; GOMIDE et al., 2001).

Outra variável que afeta o desempenho animal é a taxa de desaparecimento de forragem, a qual varia devido às alterações na quantidade de forragem perdida, sobretudo em condições de baixa eficiência

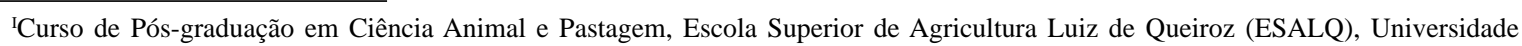
de São Paulo (USP), Piracicaba, SP, Brasil.

"Curso de Zootecnia, Universidade do Estado de Santa Catarina (UDESC), Chapecó, SC, Brasil.

"I'Curso de Pós-graduação em Ciência Animal, UDESC, Lages, SC, Brasil.

IVPrograma de Pós-graduação em Ciência Animal, UDESC, 88502-970, Lages, SC, Brasil. E-mail: dimas.oliveira@udesc.br. Autor para correspondência. 
de pastejo (CORRÊA \& MARASCHIN, 1994). O aumento da oferta de forragem apresenta como consequência acréscimo contínuo da taxa de desaparecimento de forragem (STUTH et al., 1981). Porém, o consumo pode permanecer constante, indicando que a forragem que desapareceu não foi consumida sendo perdida pelo pisoteio, deposição de fezes e morte de tecidos (BRAGA et al., 2007).

São poucos os estudos avaliando diferentes ofertas de forragem em pastagens tropicais, quando comparados aos com pastagens temperadas. Assim, o objetivo deste trabalho foi avaliar o efeito de diferentes ofertas de forragem em pastagem de estrela africana (Cynodon nlemfuensis Vanderyst var. nlemfuensis), sobre a taxa de desaparecimento de forragem e a produção de leite de vacas mestiças Holandês x Gir.

\section{MATERIAL E MÉTODOS}

O experimento foi conduzido na Fazenda Experimental Santa Mônica (43 $42^{\prime}$ 'Oeste, $22^{\circ} 21^{\prime}$ Sul), da Embrapa Gado de Leite no município de Valença-RJ, durante os meses de dezembro de 1999 a março de 2000. Foram utilizadas 30 vacas mestiças Holandês $x$

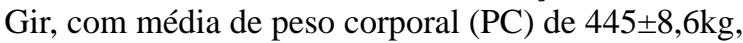
mantidas em piquetes de pastagem de estrela africana (Cynodon nlemfuensis Vanderyst var. nlemfuensis), com 0,5ha cada.

O delineamento experimental foi inteiramente casualizado com três tratamentos e três repetições. Todos os animais foram submetidos aos mesmos níveis de ofertas de forragem (OF), sendo 10,0, 12,5 e 15,0\% do peso corporal (PC). $\mathrm{O}$ ajuste da oferta de forragem foi realizado por meio do aumento da massa de forragem inicial disponível ao pastejo. O sistema de pastejo utilizado foi o rotativo com dois dias de ocupação e 24, 28 e 32 dias de descanso para as ofertas de 10,0, 12,5 e 15,0\%, respectivamente. As ofertas de forragem foram determinadas segundo a equação proposta por SOLLENBERGER et al. (2005), em que a OF $=\{$ [(massa de forragem pré-pastejo/ dias de ocupação) + taxa de acúmulo de forragem]* área do piquete $\}$ / carga animal. Os dados utilizados para o cálculo encontram-se na tabela 1 .

Os animais receberam individualmente $4,0 \mathrm{~kg}$ (base natural, com $87 \%$ de matéria seca) de um suplemento concentrado, duas vezes ao dia, após as ordenhas da manhã e tarde, representando 0,89\% do PC. A composição do concentrado foi a seguinte: milho moído 58,5\%, farinha de peixe 25\%, farelo de soja 5,5\%, farelo de trigo 5,5\% e premix vitamínico-mineral 5,5\%. Salienta-se que o experimento foi realizado antes da vigência da Instrução Normativa $n^{0} 08$ do MAPA, de 25 de março de 2004, que proibiu o uso de subprodutos de origem animal na alimentação de ruminantes.

As massas de forragem em pré e pós-pastejo foram determinadas por meio do corte, a $10 \mathrm{~cm}$ do solo, de toda a forragem contida no interior de um círculo de 0,25 $\mathrm{m}^{2}$ de área, sendo 10 amostras por piquete, escolhidas ao acaso. As amostras foram pesadas e secas em estufa com circulação de ar para determinação da matéria seca (MS) de acordo com o AOAC (1997). A composição morfológica foi determinada, manualmente, por meio de amostragem nos piquetes antes da entrada e após a saída dos animais. A taxa de acúmulo de forragem (TAF) foi calculada de acordo com PEDREIRA (2002), utilizando as massas de forragem pré e pós-pastejo.

A taxa de desaparecimento de forragem (TDF) em kg MS ha-1 dia $^{-1}$ foi calculada com base na diferença entre a massa de forragem pré e pós-pastejo $(\mathrm{kg} \mathrm{MS} \mathrm{ha-1)}$ mais a taxa de acúmulo de forragem em função do número de dias.

A produção de leite foi medida diariamente e individualmente, nas duas ordenhas, realizadas às $6 \mathrm{~h}$ e às $14 \mathrm{~h}$. As análises estatísticas foram realizadas por meio do procedimento REG do programa estatístico SAS (2002).

\section{RESULTADOS E DISCUSSÃO}

Constatou-se efeito negativo da oferta de forragem (OF) sobre a produção de leite $(\mathrm{P}<0,001$; Produção de leite $(\mathrm{PL})=20,95-0,27^{*} \mathrm{OF}, \mathrm{r}^{2}=0,94$; Figura 1 ). A produção de leite variou de 15,2 a 18,5kg vaca ${ }^{-1}$ dia $^{-1}$ e as produções médias em kg vaca ${ }^{-1}$ dia $^{-1}$ foram $18,1 \pm 0,30,17,7 \pm 1,0$ e $16,7 \pm 1,08$, para as OF de 10,0 12,5 e $15,0 \%$, respectivamente. Assim, com aumento das OF, houve redução linear da produção de leite que pode ser explicada pelos aumentos das proporções de colmo+bainha, material senescente e morto (Tabela 1), diminuindo a qualidade da forragem disponível para consumo, reduzindo a ingestão de nutrientes. Resultados semelhantes foram encontrados por

Tabela 1 - Composição morfológica da pastagem, massas de forragem pré e pós-pastejo (kg MS ha ${ }^{-1}$ ) e taxa de acúmulo de forragem (kg MS $\mathrm{ha}^{-1} \mathrm{dia}^{-1}$ ) em função de diferentes ofertas de forragem em estrela africana (Cynodon nlemfuensis Vanderyst var. nlemfuensis)

\begin{tabular}{lcccccc}
\hline Oferta de forragem & \% folha & $\begin{array}{c}\text { \% colmo } \\
\text { bainha }\end{array}$ & $\begin{array}{c}\text { \% material } \\
\text { senescente }\end{array}$ & $\begin{array}{c}\text { Relação } \\
\text { folha: colmo }\end{array}$ & MF pré-pastejo & $\begin{array}{c}\text { MF pós-pastejo } \\
\text { Taxa de acúmulo } \\
\text { de forragem }\end{array}$ \\
\hline 10,0 & 58,0 & 38,8 & 3,2 & 1,49 & 2496 & 1184 \\
12,5 & 53,7 & 41,8 & 4,5 & 1,28 & 3130 & 1215 \\
15,0 & 39,7 & 52,1 & 8,2 & 0,76 & 3841 & 68,7 \\
\hline
\end{tabular}


GOMIDE et al. (2001) em pastagem de Brachiaria decumbens com OF de 4,0 e 8,0\%.

Cabe ressaltar que, por consequência do ajuste da OF ter sido realizado por meio do aumento da massa de forragem e não da área dos piquetes, a pastagem alcançou um estádio de maturação maior, com menor quantidade de folhas e menor valor nutricional, impossibilitando a elevação da produção de leite para todas as OF praticadas. Em pastagens tropicais, altas OF refletem em tendência de redução na qualidade da forragem, principalmente por elevação do percentual de partes da planta com maiores concentrações de fibra em detergente neutro (FDN), no qual o consumo é afetado em decorrência de estrutura de dossel menos favorável ao pastejo, caracterizado por uma menor relação folha: colmo e aumento de material senescente (GOMIDE et al., 2001), resultando no consumo de dieta com menor taxa de digestão.

De acordo com HODGSON (1990), os níveis máximos de desempenho animal em pastejo estão relacionados com uma OF de 10,0 a 12,0\%. Portanto, as OF praticadas em nosso estudo já se encontravam na faixa do valor ótimo sugerido por esse autor, o que pode explicar em partes o efeito negativo do aumento das OF sobre a produção de leite.

Houve influência da OF sobre a taxa de desaparecimento de forragem (TDF) $(\mathrm{P}<0,001$; TDF=$1010,80+140,0 * \mathrm{OF}, \mathrm{r}^{2}=0,99$; Figura 1) e, para cada unidade de acréscimo da OF, a TDF aumentou 140,0kg ha $^{-1} \operatorname{dia}^{-1}$. Sendo a TDF uma variável que agrega os dados de ingestão da pastagem e perdas pelo pastejo, situações de altas OF possibilitam uma maior seleção da dieta pelos animais, com consequente diminuição da eficiência de pastejo em função das perdas de forragem. Os resultados encontrados no presente estudo condizem com os de STUTH et al. (1981), os quais observaram que a variação na oferta, de 1,0 a 35,0\% do PC/dia em pastagens de Cynodon dactylon e Panicum coloratum, causou efeito linear crescente sobre a TDF. Condizem também com aqueles encontrados por BRAGA et al. (2007) em Brachiaria brizantha cv. Marandu, nos quais a TDF respondeu positivamente ao incremento da $\mathrm{OF}$, a qual variou de 5,0 a 20,0\% do PC, sendo a TDF superior à taxa de consumo assumida $(1,7 \%)$, indicando que a forragem que desapareceu não foi ingerida, sendo então perdida.

Sugere-se que o aumento da TDF foi consequência do incremento das perdas pelo pastejo, devido à elevação da OF resultar em incremento da massa pós-pastejo (Tabela 1). Assim, a forragem que desapareceu e não foi ingerida foi perdida pela deposição de fezes, morte dos tecidos e pisoteio dos animais. Esses resultados podem ter ocorrido em virtude do nível de utilização da forragem acumulada diminuir à medida que a OF aumenta (CUNHA, 2006). Dessa forma, observou-se que, em pastagem com alta OF, há aumento nas perdas decorrentes do pastejo e incremento do material senescente, reduzindo o nível de utilização da forragem disponível.

Com o incremento da OF de 10,0 para 15,0\%, a relação folha:colmo diminuiu de 1,49 para 0,76 . Nesse sentido, PINTO et al. (1994) consideraram limite crítico da relação folha:colmo igual a 1,0 para gramíneas tropicais, sugerindo que as OF praticadas nesse estudo afetaram negativamente o valor nutritivo da forragem com impactos na produção dos animais.

Houve efeito linear da relação folha:colmo sobre a produção de leite $(\mathrm{P}<0,05$; $\mathrm{PL}=$ 15,26+1,88*relação folha:colmo; $\mathrm{r}^{2}=0,99$; Figura 2). Essa

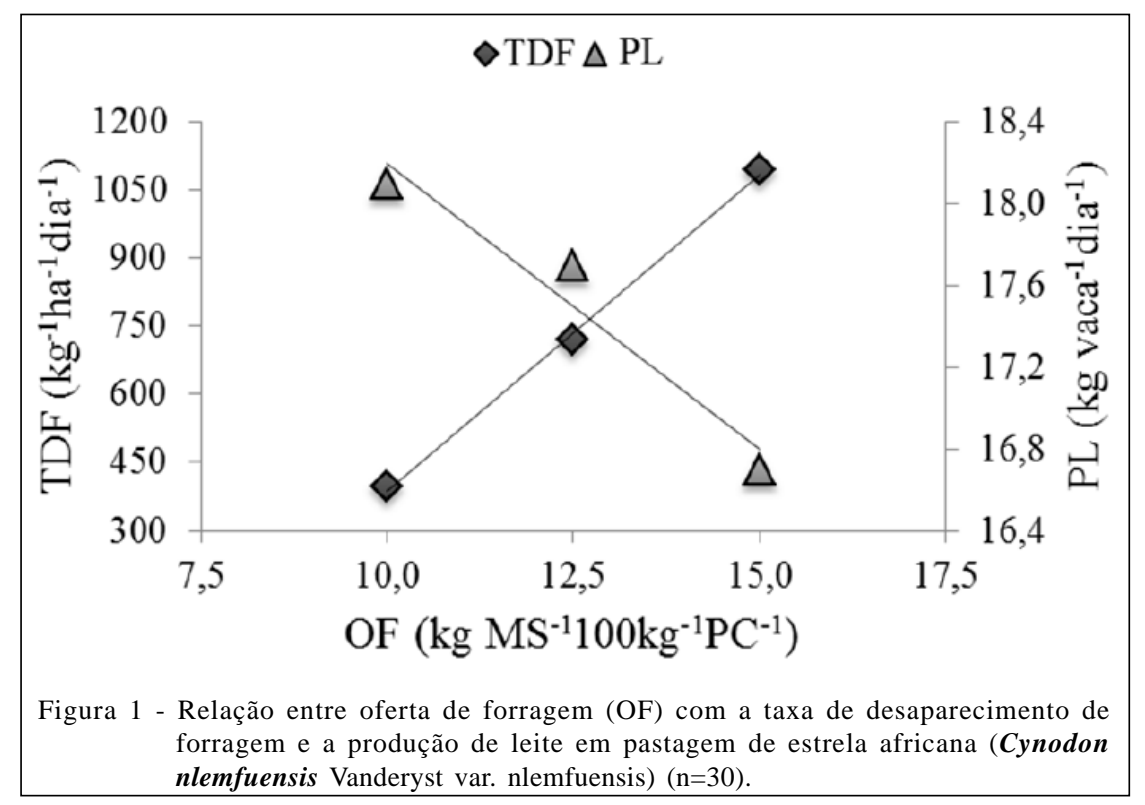

Ciência Rural, v.42, n.5, mai, 2012. 


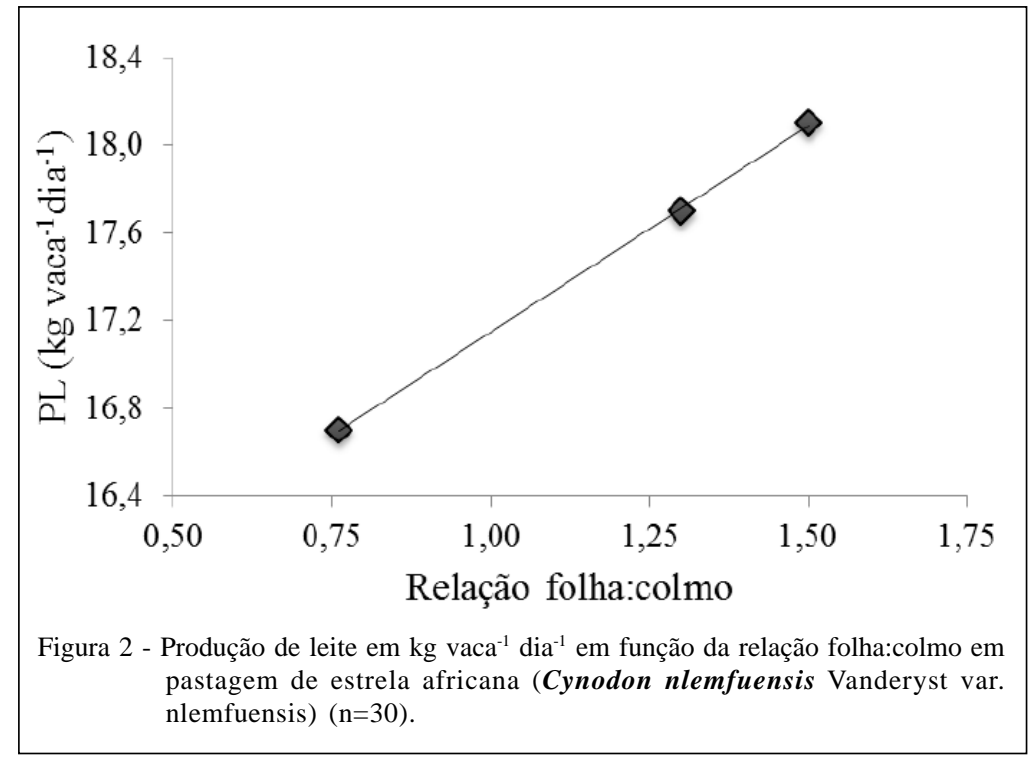

relação é uma característica importante da pastagem que apresenta impacto significativo no valor nutritivo da forrageira, sendo que, de acordo com QUEIROZ FILHO et al. (2000), quando a relação é elevada, a forragem apresenta maior teor de proteína, digestibilidade e consumo. Assim, no presente estudo, constatou-se que a menor OF empregada proporcionou maior relação folha:colmo, possibilitando aos animais selecionar e ingerir maior quantidade de folhas, explicando os valores mais altos de produção de leite encontrados com a menor OF. Em contrapartida, quando a OF foi elevada, houve redução da proporção de folhas na pastagem, resultando em maior oferta de componentes no dossel com menor valor nutritivo.

\section{CONCLUSÃO}

Ofertas de forragem acima de $10 \%$ em Cynodon nlemfuensis não resultaram em aumentos na produção de leite e alteraram as proporções entre os componentes morfológicos da pastagem, reduzindo a relação folha:colmo e aumentando a taxa de desaparecimento de forragem.

\section{COMITÊ DE ÉTICA E BIOSSEGURANÇA}

Declaro, para os devidos fins, que os animais utilizados e constantes da metodologia desse artigo foram tratados com ética e não sofreram nenhum tratamento invasivo ou que causasse dor e/ou desconforto.

O trabalho e todos os métodos nele empregados são de total responsabilidade dos autores.

\section{REFERÊNCIAS}

AOAC - Official of analysis of the Association of Official Analytical Chemists. 14.ed. Washington: Williams Horwitz, 1997. 1141p.

BRAGA, G.J et al. Eficiência de pastejo de capim-marandu submetido a diferentes ofertas de forragem. Pesquisa Agropecuária Brasileira, v.42, n.11, p.1641-1649, 2007. Disponível em: <http://www.scielo.br/pdf/pab/v42n11/ v42n11a17.pdf >. Acesso em: 25 ago. 2010. doi: 10.1590/ S0100-204X2007001100017.

CORRÊA, F.L.; MARASCHIM, G.E. Crescimento e desaparecimento de uma pastagem nativa sob diferentes níveis de oferta de forragem. Pesquisa Agropecuária Brasileira, v.29, n.10, p.1617-1623, 1994 . Disponível em: <http:// webnotes.sct.embrapa.br/pdf/pab1994/outubro/ pab17_out_94.pdf>. Acesso em: 15 ago. 2010.

COWAN, R.T. et al. Influence of level of concentrate feeding on milk production and pasture utilization by Friesian cows grazing tropical grass-legume pasture. Australian Journal of Experimental Agriculture and Animal Husbandry, v.17, p.373-379, 1977. Disponível em: <http://www.publish.csiro.au/ paper/EA9770373.htm>. Acesso em: 21 ago. 2010. doi:10.1071/EA9770373.

CUNHA, M.V. Características estruturais e morfológicas relacionadas à eficiência de pastejo em Pennisetum sp. no período de seca. 2006. 105f. Dissertação (Mestrado em Zootecnia) - Programa de Pós-graduação em Zootecnia, Universidade Federal Rural de Pernambuco, PE.

CURRAN, J. et al. Sward characteristics, grass dry matter intake and milk production performance are affected by pre-grazing herbage mass and pasture allowance. Livestock Science, v.127, p.144-154, $2010 . \quad$ Disponível em: <http:// www.livestockscience.com/article/S1871-1413(09)00304-7/ 
pdf $>$. Acesso em: 28 ago. 2010. doi:10.1016/ j.livsci.2009.09.004.

GOMIDE, J.A. et al. Consumo e produção de leite de vacas mestiças em pastagem de Brachiaria decumbens manejada sob duas ofertas diárias de forragem. Revista Brasileira de Zootecnia, v.30, n.4, p.1194-1199, 2001. Disponível em: <http://www.scielo.br/pdf/rbz/v30n4/6024.pdf >. Acesso em: 06 set. 2010. doi: 10.1590/S1516-35982001000500 009.

GONÇALVES, G.D. et al. Produção e valor nutritivo de gramíneas do gênero Cynodon em diferentes idades ao corte durante o ano. Acta Scientiarum, v.24, n.4, p.1163-1174, 2002. Disponível em: <http://periodicos.uem.br/ojs/index.php/ ActaSciAnimSci/article/viewFile/2582/1761>. Acesso em: 04 set. 2010 .

HODGSON, J. Grazing management: Science into practice. London: Longman scientific and technical, 1990. 203p.

MAPA. Pró́be em todo o território nacional a produção, a comercialização e a utilização de produtos destinados a alimentação de ruminantes que contenham em sua composição proteínas e gorduras de origem animal. Brasília: Diário Oficial da União, Instrução Normativa n.08, de 25 de março de 2004.

McEVOY, M. et al. The effect of herbage allowance and concentrate supplementation on milk production performance and dry matter intake of spring-calving dairy cows in early lactation. Journal of Dairy Science, v.91, p.1258-1269, 2008. Disponível em: <http://download.journals.elsevierhealth.com/ pdfs/journals/00220302/PIIS0022030208713845.pdf>. Acesso em: 24 ago. 2010. doi:10.3168/jds.2007-0710.

PEDREIRA, C.G.S. Avanços metodológicos na avaliação de pastagens. In: REUNIÃO ANUAL DA SOCIEDADE BRASILEIRA DE ZOOTECNIA, 39., 2002, Recife, Pe. Anais... Recife: Sociedade Brasileira de Zootecnia, 2002. CDROM.

PINTO, J.C. et al. Produção de matéria seca e relação folha/ caule de gramíneas forrageiras tropicais, cultivadas em vasos, com duas doses de nitrogênio. Revista Brasileira de Zootecnia, v.23, n.3, p.313-326, 1994. (Versão impressa).

QUEIROZ FILHO, J.L. et al. Produção de matéria seca e qualidade do capim-elefante (Pennisetum purpureum Schum.) cultivar roxo em diferentes idades de corte. Revista Brasileira de Zootecnia, v.29, n.1, p.69-74, 2000. Disponível em: <http:/ /www.scielo.br/pdf/rbz/v29n1/5733.pdf>. Acesso em: 20 ago. 2010. doi: 10.1590/S1516-35982000000100010.

REIS, R.A. et al. Produção de fenos de Cynodon. In: VILELA, D. et al. Cynodon: forrageiras que estão revolucionando a pecuária brasileira. Juiz de Fora: EMBRAPA Gado de Leite, 2005. Cap.4, p.79-131.

RIBEIRO FILHO, H.M.N. et al. Consumo de forragem e produção de leite de vacas em pastagem de azevém-anual com duas ofertas de forragem. Revista Brasileira de Zootecnia, v.38, n.10, p.2038-2044, 2009. Disponível em: <http:// www.scielo.br/pdf/rbz /v38n10/26.pdf>. Acesso em: 15 ago. 2010. doi: 10.1590/S1516-35982009001000026.

SAS, Statistical Analisys System: user's guide, Stat. 9.ed. Cary, 2002. 968p.

SILVA, M.W.R. Características estruturais, produtivas e bromatológicas das gramíneas Tifton 85, Marandu e Tanzânia submetidas à irrigação. 2009. 55f. Dissertação (Mestrado em Zootecnia) - Programa em Pós-graduação em Zootecnia. Universidade Estadual do Sudoeste da Bahia, BA.

SOLLENBERGER, L.E. et al. Reporting forage allowance in grazing experiments. Crop Science, v.45, p.896-900, 2005. Disponível em: <https://www.agronomy.org/publications/cs/ articles/45/3/0896>. Acesso em: 25 abr. 2005. doi:10.2135/ cropsci2004.0216.

STOBBS T.H. Short term effects of herbage allowance on milk production, milk composition and grazing time of cows grazing nitrogen fertilising tropical grass pasture. Australian Journal of Experimental Agriculture and Animal Husbandry, v.17, p.892-898, 1977. Disponível em: <http://www.publish.csiro.au/ paper/EA9770892.htm>. Acesso em: 14 ago. 2010. doi:10.1071/EA9770892.

STRADIOTTI Jr., D. Consumo e produção de leite de vacas sob três ofertas de pasto em pastagem de capimelefante anão (Pennisetum purpureum, cv. "Mott”). 1995. 61f. Dissertação (Mestrado em Forragicultura e Pastagens) Programa de pós-graduação em Zootecnia, Universidade Federal de Viçosa, MG.

STUTH, J.W. et al. Effect of herbage allowance on the efficiency of defoliation by the grazing animal. Grass and Forage Science, v.36, p.9-15, 1981. Disponível em: <http:// onlinelibrary.wiley.com/doi/10.1111/j.136594.1981.tb01533.x/pdf >. Acesso em: 14 ago. 2010. doi: 10.1111/j.1365-2494.1981.tb01533.x. 